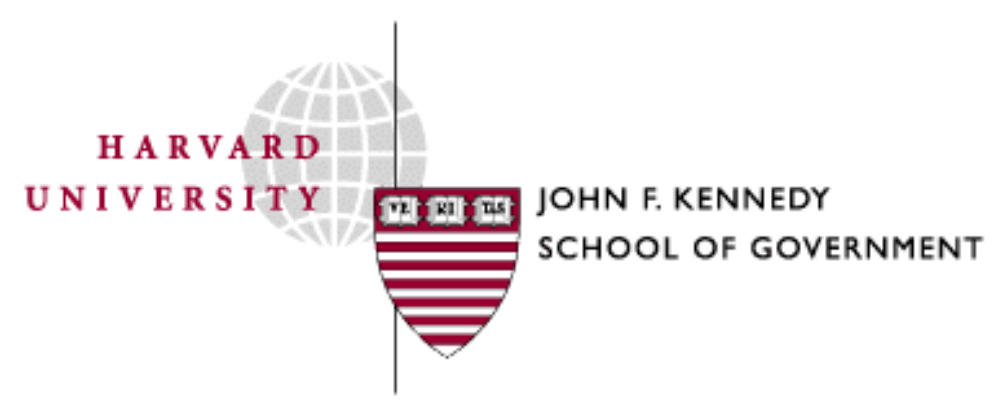

Faculty Research Working Papers Series

Deciding on Monetary Integration: An Operational Approach

\author{
Andrew Powell \\ Inter-American Development Bank and Universidad Torcuato Di Tella \\ Federico Sturzenegger \\ John F. Kennedy School of Government - Harvard University \\ and Universidad Torcuato Di Tella
}

September 2007

RWP07-041

The views expressed in the KSG Faculty Research Working Paper Series are those of the author(s) and do not necessarily reflect those of the John F. Kennedy School of Government or of Harvard University. Faculty Research Working Papers have not undergone formal review and approval. Such papers are included in this series to elicit feedback and to encourage debate on important public policy challenges. Copyright belongs to the author(s). Papers may be downloaded for personal use only. 


\title{
Deciding on Monetary Integration: An Operational Approach ${ }^{1}$
}

\author{
Andrew Powell ${ }^{2}$ \\ Inter-American Development Bank and \\ Universidad Torcuato Di Tella \\ and \\ Federico Sturzenegger \\ Harvard University and \\ Universidad Torcuato Di Tella
}

\begin{abstract}
We develop a simple n-country model to consider the costs and benefits of joining a monetary union. Our factor-OCA framework encompasses different approaches and allows us to consider the optimal composition of a monetary union for all the potential members. We illustrate the model in practice with various simulations and we develop two empirical applications based on expanding EMU and on whether there would be a benefit to deepening Nafta to be a monetary union. While some commentators have called for a one-world currency, we find full monetary integration has costs for some countries and benefits for others, perhaps explaining why this remains a controversial issue.
\end{abstract}

September 2007

\footnotetext{
${ }^{1}$ We thank Guillermo Calvo, Antoni Estavadeordal, Ernesto Stein, Alan Taylor and Andrés Velasco for comments on the paper. We also thank participants at the following seminars and conferences: Univerisdad Torcuato Di Tella seminar series, brainstorming session in Cambridge, USA on "FTAA and beyond", "FTAA and Beyond" conference held in Punta del Este, Uruguay and the Lacea conference for useful comments. All mistakes naturally remain our own. The views expressed in this paper do not necessarily reflect the views of the Inter-American Development Bank or any other institution.

${ }^{2}$ Corresponding author, address: Inter-American Development Bank, Research Department, Stop B-900, 1300 New York Avenue NW, Washington DC 20577, tel 202623 3209, fax 202623 2481, email: andrewp@iadb.org.
} 


\section{Introduction}

Mundell (1961), Mckinnon (1963) and Poole (1970) provided pathbreaking theoretical models to consider when countries should consider adopting a common currency. These papers gave rise to what are now referred to as the Optimal Currency Area (OCA) conditions. OCA theory has hence become an essential element of the toolkit of international economists and these earlier papers have now spawned a wide literature $^{1}$. Several OCA models are essentially two-country, suggesting when a country should "fix" to another country often thought of as the rest of the world. Such models are then restrictive in analyzing a set of important issues, such as what is the effect on a third country when two other trading partners form a monetary union and how two current members of a monetary union are affected if a third, fourth and fifth country joins in and (hence) what the optimal membership of a monetary union might be for a particular country. A notable exception is the paper by Alesina, Barro and Tenreyro (2002) - ABT. They consider various elements of the debate including credibility and co-movements. As Rose points out commenting on ABT, this paper has made progress on considering whether a country should join a currency union but the work is not yet finished especially in terms of trying to quantifying the costs and benefits of membership of a particular agreement ${ }^{2}$. We attempt here to develop a simple theoretical approach to quantifying the costs and benefits of a country joining a monetary union but one that can be made operational.

These are not simply interesting theoretical issues but they are also of significant practical importance. In the context of EMU, 12 countries have now adopted the single currency. The EU enlargement process implies that there are now $25 \mathrm{EU}$ countries and hence a large number of potential new members. Was EMU a good deal for its members, would it be beneficial if, say, the UK joined and what is the potential effect of the UK joining EMU on other nations? NAFTA has to date only encompassed a trade agreement but there has been a debate in both Mexico and Canada whether it should not also encompass a single currency. Would this be beneficial for the three countries involved, should Chile join in? What would be the effect on other countries? Some commentators continue to call for a single world currency or at least an agreement between the three large monetary areas (the US, EMU

\footnotetext{
${ }^{1}$ See for example Bayoumi (1994) for a formal model of OCAs, Bayoumi and Eichengreen (1994) on OCA and Nafta, Bean (1992) on OCA and Europe, Buiter (1999) on OCA and the UK, and Masson and Taylor (1993) and Willett (1999) for reviews.

${ }^{2}$ Andrew Rose's comment is available: http://faculty.haas.berkeley.edu/arose/ABT.pdf
} 
and Japan). Would this be beneficial and how would such an agreement affect other countries? Most existing models do not capture the multicountry aspects involved in these questions. This paper constitutes a first attempt at developing a simple framework capable of considering these various different interaction effects. We develop what might be considered a "reduced form" version of a OCA model and extend it to the case of $n$ countries. Given the similarities, our model might be described as the Factor Approach meets OCA.

In particular, we assume countries are affected by four types of shocks; idiosyncratic and systemic shocks, both real and monetary in nature. We then develop equations for GDP volatility as a function of simple underlying characteristics of countries and, in particular, their dependence on systemic shocks (a type of beta coefficient), the size (volatility) of the idiosyncratic shocks, and the choice of exchange rate regime. While we label shocks as real or monetary, they can be interpreted more widely as shocks to which it would be desirable for the exchange rate to respond, and shocks that might shift the nominal exchange rate away from some desired path (in terms of GDP stabilization), respectively. This relatively simple framework allows us to consider the effect of a monetary union in a subset of countries on the members of the union and on other countries. We illustrate these and other points in a set of simulations.

We also provide a set of empirical applications of the model. We conduct a factor analysis that exstracts one real and one monetary systemic factor from the data. In VAR exercises we check that our factors do indeed correspond to the above mentioned shocks and then use the VAR results to decompose movements in GDP and exchange rates into the systemic dependence of each country on those factors and idiosyncratic movements. To illustrate the model in practice, we consider two specific simulations in the empirical section. The first is based on EMU, and we consider whether this monetary arrangement is beneficial for its members, whether the UK should join, and the effect of the introduction of the Euro on other countries. We also consider what would happen if EMU were then extended to a world currency. A second simulation starts with Nafta where we consider whether it would be beneficial for the US, Canada and Mexico to form a monetary union, and the effect of such a monetary union on other countries - for example Chile. We also ask the question whether Japan and EMU members and other countries should join to form a one world currency.

The paper proceeds as follows. In the next section, we provide the basic theoretical model. In section 3 we then consider a set of initial simulations regarding CU's and dollarization. In section 4 we present 
the empirical application and simulations and section 5 concludes.

\section{The Model}

\subsection{A reduced form $n$ country OCA model}

Our model is a reduced form version of the OCA conditions inspired by the early work of Mundell and Poole but that we think nests many views regarding the costs and benefits of currency unions. We start with a world of floating exchange rates between $n$ countries and an initial equation for output for each country $i$ of the form:

$$
\Delta G D P_{i}=\Delta R_{i}-\frac{\alpha}{n-1} \sum_{j=1}^{n-1} \Delta s_{i j} w_{i j}
$$

In this specification, real shocks $\Delta R_{i}$, which affect output directly, can be smoothed by exchange rate adjustments $\Delta s_{i j}$ against the $n-1$ other countries. Here, $\alpha$ is the smoothing effect of the nominal exchange rate movement and $w_{i j}$ is a weight respresenting the importance of the parity with country $j$ to smooth country $i$ GDP. More succinctly we can write this equation as:

$$
G=R-\alpha\left(S . W^{T}\right)^{D}
$$

Where $G$ and $R$ are $(n * 1)$ column vectors of the change in GDP and the real shocks for the $n$ countries respectively, $S$ is a $n * n$ matrix of the change in the bilateral exchange rates, $W^{T}$ is the transpose of the $(n * n)$ matrix of weights and $(.)^{D}$ refers to the diagonal elements of a matrix such that $\left(S . W^{T}\right)^{D}$ is the $(n * 1)$ column vector of the diagonal elements of $S . W^{T}$. Note that the diagonal elements of $S$ and the diagonal elements of $W$ are all equal to zero and that the elements of $S$ are such that $s_{i j}=-s_{j i}$. The $W$ matrix of weights, however, is not symmetric (the US\$/Mexican peso exchange rate is more important for Mexico to smooth Mexican GDP than for the US to smooth US GDP).

We assume that each bilateral exchange, is determined by a "monetary approach to the exchange rate" equation as follows:

$$
\Delta s_{i j}=\left(\Delta G D P_{i}-\Delta G D P_{j}\right)-\left(\Delta M_{i}-\Delta M_{j}\right),
$$

where, a positive (negative) shock to output $(\triangle G D P)$ or a negative

(positive) monetary shock $(\Delta M)$ for country $i$ (country $j$ ) results in an exchange rate appreciation. 
In this set-up the monetary shocks should be interpreted as deviations from an optimal monetary policy rule and represents the fact that under floating the monetary supply cannot be perfectly controlled. The special case of perfect monetary control can be translated into our model with the assumption that the monetary shocks have a variance of zero and the alpha parameter is large. GDP volatility under a float would then be close to zero, even in the presence of real shocks. Our model captures a more general view that there are certain limitations to using monetary policy in this way and that monetary variables may not be totally within the control of the monetary authorities ${ }^{3}$. In contrast, under fixed exchange rates, the stock of nominal money is endogenous to shocks to real money demand. However, our assumption is that as the exchange rate remains fixed this endogenous adjutsment in nominal money does not affect $\mathrm{GDP}^{4}$.

All of the elements of the exchange rate matrix, $S$ are determined simply by knowing all of the bilateral exchange rates of one country. Consider country number 1 , equation 2 for all the bilateral exchange rates of country 1 may then be written as:

$$
S_{1}=G_{1}-G-\left(M_{1}-M\right),
$$

where $S_{1}$ is an $(n-1) * 1$ vector of the changes in bilateral exchange rates for country $1, G_{1}$ is a $(n-1) * 1$ vector with each element being the change in GDP of country $1, G$ is now an $(n-1) * 1$ vector of the changes in GDP for each country excluding country $1, M_{1}$ is an $(n-1) * 1$ vector with each element being the monetary shock pertaining to country 1 and $M$ is an $(n-1) * 1$ vector of the monetary shocks for each country excluding country 1 . To fill the $S$ matrix, it is enough to note that, $s_{i j}=s_{1 j}-s_{1 i},(i \neq j, i \neq 1, j \neq 1)$, and to remember that the matrix is symmetric and the diagonal elements zero $\left(s_{i j}=-s_{j i}, s_{i i}=0\right)$.

Equations 1 and 4 form a system of $n+(n-1)$ equations where the unknowns are the $n$ changes in $G D P$ and the $n-1$ bilateral exchange rates with country 1 . In general, except where countries are symmetric, analytical results are not available for the solution to this system. We return later to a special symmetric case, where countries are considered

\footnotetext{
${ }^{3}$ As Buiter (1999) puts it, perhaps too strongly, "... objections to UK (EMU membership) are based on the misapprehension that independent monetary policy, and the associated nominal exchange rate flexibility, can be used effectively to offset or even neutralise asymmetric shocks. This 'fine-tuning delusion' is compounded by a failure to understand that, under a high degree of international financial integration, market determined exchange rates are primarily a source of shocks and instability" (quoted from the abstract of the paper).

${ }^{4}$ This specification can be seen as a reduced form of a general equuilibrium model with incomplete markets as for example that suggested by Neumeyer (1998).
} 
identical and hence the matrix of weights is uniform where we are able to compute analytical solutions. However, as the system is linear the solution may be written in the form:

$$
G=A \cdot R+B \cdot M
$$

where $A$ and $B$ are $n * n$ matrices with each element being functions of the weights and the parameter, $\alpha$.

Under a regime of a single world currency it is clear that $s_{i j}=0$ for all currencies and hence from Equation 1, $G=R^{5}$.Comparing this equation with Equation 5, GDP volatility may be lower under floating if each element of $A . R$ is numerically less than each element of $R$. This illustrates the potential for floating exchange rates to smooth the real shocks. However, the cost of floating is that nominal or monetary shocks may affect real GDP through exchange rate movements $(B . M)$. It follows from the above that floating exchange rates will stabilize the GDP of all countries if ${ }^{6}$ :

$$
|A . R+B . M|<|R|
$$

Or alternatively if monetary shocks are sufficiently small:

$$
|M|<\left|B^{-1} \cdot[(I-A) \cdot R]\right|
$$

Where $I$ is the identity matrix. The benefit to choosing a floating exchange rate is then that the exchange rate can act as a shock absorber in the case of real shocks but floating also introduces the possibility of monetary shocks that tend to move the exchange rate away from a desired smoothing path. In this specification, real shocks can be terms of trade, productivity or capital flow disturbances (sudden stops). Monetary shocks can relate to money supply disturbances or changes in money demand not related to the real side of the economy. The important aspect of our monetary shocks is that they are shocks that drive the exchange rate away from desired changes given the confluence of real shocks. ${ }^{7}$. Relating the model to the early work of Mundell

\footnotetext{
${ }^{5}$ As discussed in this case $M$ is endogenous and hence plays no role.

${ }^{6} \mathrm{~A}$ world social planner might consider whether the Norm of $R$ is greater or smaller than the Norm of $A . R+B . M$ to decide if the world is better off with floating rates or a one world currency. This would weight each country's GDP volatility equally in a world loss function. In this paper we do not go further into issues of world welfare.

${ }^{7}$ We note that this set up abstracts from the ever-growing list of "new considerations" that various authors have suggested should be included within OCA theory.
} 
and others, countries that suffer large "monetary" shocks may find they should fix whereas countries with low monetary shocks but that suffer larger "real" shocks should float and use the exchange rate to smooth those real disturbances.

Note that the presence of Sudden Stops - see for example Calvo (2002) - might be thought of as a systemic real shock. Sudden Stops impact the real economy through a decline in available funds for investment and in general require a significant current account adjustment. These are then shocks where it would in general be advantageous to respond with exchange rate flexibility. To the extent that a group of countries suffer from such a shock simultaneously implies that the cost of a monetary union between those countries would be low, although if an individual country was more prone to such a "sudden stop" then individual exchange rate flexibility would clearly be an advantage.

In short, this specfication provides a unifying framework and allows for a high degree of flexibility to take into account a wide variety of issues that have been discussed in the literature.

\subsection{A factor approach to OCA}

So far we have not defined what the real and the monetary shocks are. In what follows we assume that there are individual and systemic real and monetary shocks. This is the reason we label our specification a factor approach to OCA. In particular we assume that each country's real shock $\Delta R_{i}$ has both a systemic and an individual component:

$$
\Delta R_{i}=\beta_{i}^{R} \epsilon_{w}^{R}+\epsilon_{i}^{R}
$$

where for simplicity we assume a single systemic factor. Each country is affected directly by individual shocks $\epsilon_{i}^{R}$ or in response to world shocks $\epsilon_{w}^{R}$ with adjustment coefficient $\beta_{i}^{R}$. Monetary shocks follow the same pattern with systemic and independent components:

$$
\Delta M_{i}=\beta_{i}^{M} \epsilon_{w}^{M}+\epsilon_{i}^{M} .
$$

In each case we assume that the individual shocks are independent with respect to each other and of course with respect to the systemic

Willett (1999) includes as (new) considerations, "optimal public finance, the degree of international currency substitution, the new classical view of policy effectiveness, the informativeness of price and quantity signals, the controllability of the money supply, time inconsistency problems and credibility issues". 
shocks. Using these definitions of the real and monetary shocks, changes in GDP are then given by:

$$
G=A \cdot \epsilon_{I}^{R}+\epsilon_{w}^{R}\left(A \cdot \beta^{R}\right)+B \cdot \epsilon_{I}^{M}+\epsilon_{w}^{M}\left(B \cdot \beta^{M}\right),
$$

where $\epsilon_{I}^{R}$ is a $(n * 1)$ vector of the individual real shocks, $\beta^{R}$ is a $(n * 1)$ vector of the senstivities or betas with respect to the world systemic shock $\epsilon_{w}^{R}$ (which is a scalar) and with similar notation for the monetary shocks. The vector of GDP variances, $V_{G D P}^{\text {Float }}$, in this world of floating exchange rates is then given by:

$$
V_{G D P}^{\text {Float }}=(A)^{2} \cdot V_{\epsilon_{I}^{R}}+\sigma_{\epsilon_{w}^{R}}^{2}\left(A \cdot \beta^{R}\right)^{2}+(B)^{2} V_{\epsilon_{I}^{M}}+\sigma_{\epsilon_{w}^{M}}^{2}\left(B \cdot \beta^{M}\right)^{2}
$$

where $V_{\epsilon_{I}^{R}}$ is an $(n * 1)$ vector of the variances of individual real shocks and $\sigma_{\epsilon_{w}^{R}}^{2}$ is a scalar representing the variance of the world real systemic shock, with similar notation for the world systemic and individual monetary shocks and where we use the notation that the square of a matrix is equal to a matrix of its own elements squared, i.e.: $(X)^{2}=\left(x_{i j}^{2}\right)$. If there is one world currency then GDP variances are given simply by:

$$
V_{G D P}^{F i x}=V_{\epsilon_{I}^{R}}+\sigma_{\epsilon_{W}^{R}}^{2} \cdot\left(\beta^{R}\right)^{2}
$$

\subsection{Partial Monetary Unions}

The advantage of this framework is that it allows us to analyze the case of monetary unions between $k(k<n)$ countries. For example, in the special case of G7, Germany France and Italy form part of EMU while the other 4 float. Suppose we assume that the rest of the world is one further country, then $n=8$ and $k=3$. With the 3 EMU members ordered as countries $1-3$, the matrix of bilateral exchange rates would look like:

$$
S=\left(\begin{array}{cccccccc}
0 & 0 & 0 & s_{m 4} & s_{m 5} & s_{m 6} & s_{m 7} & s_{m 8} \\
0 & 0 & 0 & s_{m 4} & s_{m 5} & s_{m 6} & s_{m 7} & s_{m 8} \\
0 & 0 & 0 & s_{m 4} & s_{m 5} & s_{m 6} & s_{m 7} & s_{m 8} \\
s_{4 m} & s_{4 m} & s_{4 m} & 0 & s_{45} & s_{46} & s_{47} & s_{48} \\
s_{5 m} & s_{5 m} & s_{5 m} & s_{54} & 0 & s_{56} & s_{57} & s_{58} \\
s_{6 m} & s_{6 m} & s_{6 m} & s_{64} & s_{64} & 0 & s_{67} & s_{68} \\
s_{7 m} & s_{7 m} & s_{7 m} & s_{74} & s_{74} & s_{74} & 0 & s_{78} \\
s_{8 m} & s_{8 m} & s_{8 m} & s_{84} & s_{84} & s_{84} & s_{87} & 0
\end{array}\right),
$$


where $s_{m i}$ is the exchange rate between the monetary union (EMU in this case) and the non-EMU country $i$. In this case, there are only 5 exchange rates to be determined - for example $s_{m 4} \ldots . . s_{m 8}$. We can then determine all the other bilateral exchange rates in similar mode to that above.

The exchange rate of the monetary union with its trading partners is determined by Equation 4 that becomes:

$$
S_{m}=G_{m}-G_{j}-\left(M_{m}-M_{j}\right)
$$

where $S_{m}$ is the $(n-k)$ vector of bilateral exchange rates between the monetary union and non-member countries. The definitions of $G_{m}$ and $M_{m}$ reflect the aggregaton of the country variables to that of the level of the monetary union. The simplest assumption would be to assume that each element of $G_{m}$ is given by $\frac{1}{k} \sum_{i=1, k} \Delta G D P_{i}$ and each element of $M_{m}$ given by $\frac{1}{k} \sum_{i=1, k} M_{i}$ where there are $k$ members of the monetary union. This would be most appropriate for monetary unions where members

are of a similar size. However, where members are of different sizes we assume below that each element of $G_{m}$ is given by $\sum_{i=1, k} \pi_{i} \Delta G D P_{i}$ and each element of $M_{m}$ by $\sum_{i=1, k} \pi_{i} M_{i}$ where $\sum_{i=1, k} \pi_{i}=1$ and these weights reflect the relative size of the economies in the monetary union.

\subsection{Analytical Results: the symmetric case}

In the case where all country weights are the same (ie: all non zero elements of the $W$ matrix are equal and we set them to equal $1 /(n-1)$ such that - given each diagonal element is zero - the sum of each row is unity), we obtain relatively simple analytical results. In particular, we obtain simple representations for the $A$ and $B$ matrices. For the case where all countries float we find that:

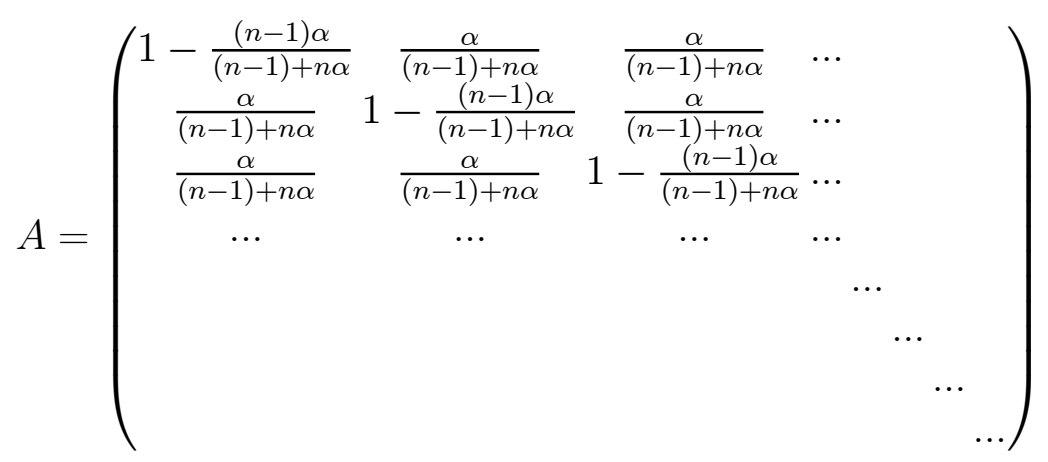




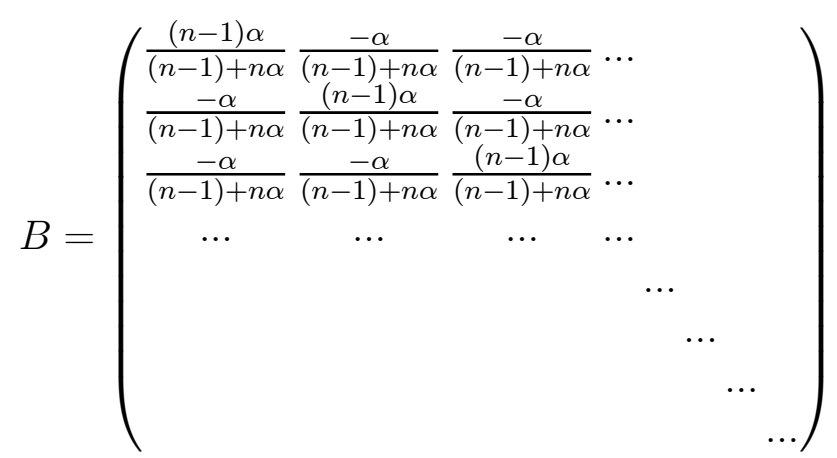

The $A$ matrix implies that a positive real shock to country $i$ increases GDP of country $i$ and a positive real shock to country $j$ also increases the GDP of country $i$ as it produces a depreciation of the relevant bilateral exchange rate, which is expansionary for $i$. The diagonal elements of $A$ represent the effect of a real shock of country $i$ on its GDP. While in the one world-currency case $(G=R)$ these terms would be equal to one, the diagonal elements of $A$ are strictly less than unity for strictly positive $\alpha$, as own-country real shocks are smoothed by exchange rate flexibility. However, note that real shocks from other countries now affect country $i$ through the movement of the flexible exchange rates while in a one world currency the off diagonal elements would all be equal to zero ${ }^{8}$.

The $B$ matrix illustrates that a positive monetary shock to country $i$ is expansionary for country $i$ (as it causes an exchange rate depreciation) whereas a positive monetary shock to country $j$ is contractionary. In general, monetary shocks in one country impact all countries through the movement of the nominal exchange rates, but own monetary shocks tend to be more important (the diagonal term is numerically larger than the off diagonal terms as own monetary shocks affect all $n-1$ bilateral exchange rates of the own country) and if countries all have monetary shocks of the same sign then they would tend to cancel each other out ${ }^{9}$.

For the case where the first $k$ countries form a monetary union we find that:

\footnotetext{
${ }^{8}$ If the real shocks of all countries are exactly the same (perfectly correlated real shocks), then the coefficients in the $A$ matrix imply that the real shocks of the $n-1$ other countries cancel out the second part of the diagonal term for country $i$ leaving only the effect of the own country shock with a coefficient of unity $\left(\sum_{j}^{n-1} \frac{\alpha}{n-1+n \alpha}=\right.$ $\left.\frac{(n-1) \alpha}{n-1+n \alpha}\right)$. Perfectly correlated real shocks then imply no benefit to floating versus a one-world currency.

${ }^{9}$ If the monetary shocks of all countries are exactly the same (perfectly correlated monetary shocks), then the coefficients in the $B$ matrix imply that the monetary shocks of the $n-1$ other countries cancel out the own country monetary shock such that monetary shocks have no effect on GDP volatility $\left(\sum_{j}^{n-1} \frac{\alpha}{n-1+n \alpha} \cdot=\frac{(n-1) \alpha}{n-1+n \alpha}\right)$.
} 


$$
\begin{aligned}
& A=\left(\begin{array}{ccccc}
1-\frac{(n-1) \alpha}{k((n-1)+n \alpha)} & \frac{-(n-k) \alpha}{k(n-1)+n \alpha} & \frac{-(n-k) \alpha}{k(n-1)+n \alpha} & \ldots & \frac{\alpha}{(n-1)+n \alpha} \frac{\alpha}{(n-1)+n \alpha} \ldots \\
\frac{-(n-k) \alpha}{k(n-1)+n \alpha} & 1-\frac{(n-1) \alpha}{k((n-1)+n \alpha)} & \frac{-(n-k) \alpha}{k(n-1)+n \alpha} & \ldots & \frac{\alpha}{(n-1)+n \alpha} \frac{\alpha}{(n-1)+n \alpha} \ldots \\
\frac{-(n-k) \alpha}{k(n-1)+n \alpha} & \frac{-(n-k) \alpha}{k(n-1)+n \alpha} & 1-\frac{(n-1) \alpha}{k((n-1)+n \alpha)} & \ldots & \frac{\alpha}{(n-1)+n \alpha} \frac{\alpha}{(n-1)+n \alpha} \ldots \\
\ldots & \ldots & \ldots & \ldots & \frac{\alpha}{(n-1)+n \alpha} \frac{\alpha}{(n-1)+n \alpha} \cdots \\
\frac{\alpha}{(n-1)+n \alpha} & \frac{\alpha}{(n-1)+n \alpha} & \frac{\alpha}{(n-1)+n \alpha} & \frac{\alpha}{(n-1)+n \alpha} \frac{(n-1)+\alpha}{(n-1)+n \alpha} \frac{\alpha}{(n-1)+n \alpha} \ldots \\
\frac{\alpha}{(n-1)+n \alpha} & \frac{\alpha}{(n-1)+n \alpha} & \frac{\alpha}{(n-1)+n \alpha} & \frac{\alpha}{(n-1)+n \alpha} \frac{\alpha}{(n-1)+n \alpha} \frac{(n-1)+\alpha}{(n-1)+n \alpha} \ldots \\
\ldots & \ldots & \ldots & \ldots & \ldots
\end{array}\right) \\
& B=\left(\begin{array}{ccccc}
\frac{(n-k) \alpha}{k((n-1)+n \alpha)} & \frac{(n-k) \alpha}{k((n-1)+n \alpha)} & \frac{(n-k) \alpha}{k((n-1)+n \alpha)} & \ldots & \frac{-\alpha}{(n-1)+n \alpha} \frac{-\alpha}{(n-1)+n \alpha} \ldots \\
\frac{(n-k) \alpha}{k((n-1)+n \alpha)} & \frac{(n-k) \alpha}{k((n-1)+n \alpha)} & \frac{(n-k) \alpha}{k((n-1)+n \alpha)} & \ldots & \frac{-\alpha}{(n-1)+n \alpha} \frac{-\alpha}{(n-1)+n \alpha} \ldots \\
\frac{(n-k) \alpha}{k((n-1)+n \alpha)} & \frac{(n-k) \alpha}{k((n-1)+n \alpha)} & \frac{(n-k) \alpha}{k((n-1)+n \alpha)} & \ldots & \frac{-\alpha}{(n-1)+n \alpha} \frac{-\alpha}{(n-1)+n \alpha} \ldots \\
\ldots & \ldots & \ldots & \ldots & \frac{-\alpha}{(n-1)+n \alpha} \frac{-\alpha}{(n-1)+n \alpha} \ldots \\
\frac{-\alpha}{(n-1)+n \alpha} & \frac{-\alpha}{(n-1)+n \alpha} & \frac{-\alpha}{(n-1)+n \alpha} & \frac{-\alpha}{(n-1)+n \alpha} \frac{(n-1) \alpha}{(n-1)+n \alpha} \frac{-\alpha}{(n-1)+n \alpha} \ldots \\
\frac{-\alpha}{(n-1)+n \alpha} & \frac{-\alpha}{(n-1)+n \alpha} & \frac{-\alpha}{(n-1)+n \alpha} & \frac{-\alpha}{(n-1)+n \alpha} & \frac{-\alpha}{(n-1)+n \alpha} \frac{(n-1) \alpha}{(n-1)+n \alpha} \ldots \\
\ldots & \ldots & \ldots & \ldots & \ldots
\end{array}\right)
\end{aligned}
$$

Where the top left corner of each matrix is characterised by $k * k$ terms for a monetary union of size $k$ (where $k<n$ ). As can be seen from the diagonal terms of $A$, the smoothing effect of the exchange rate is now reduced. The denominator of the second term of these diagonal elements is now multiplied by $k$. The exchange rate of the monetary union now reflects the real shocks of the whole monetary union and not an individual country member and hence the cost of joining a monetary union is that the exchange rate of the monetary union will not reflect so well the real shocks to that individual country. Note also that a positive idiosyncratic real shock to a country $j$ that is part of a monetary union with $i$ is contractionary for $i$ as it causes an appreciation of the common exchange rate against other currencies.

On the other hand, from the $B$ matrix, for the partial monetary union case, we can see that the monetary shocks for the members of the monetary union are also reduced in absolute size - the denominator of the elements corresponding to members of the monetary union are multiplied by $k$ and the numerator multiplied by $(n-k)$ rather than by $n-1$. The benefit of joining a monetary union is then that monetary shocks are reduced. However, a positive monetary shock to country $j$ that forms a monetary union with $i$ is expansionary for country $i$, 
as it produces a depreciation in the common exchange rate with other currencies.

Note that in this symmetric case, if the first $k$ countries form a monetary union then there is no effect on the other $n-k$ countries. This however is a result of symmetry and does not carry over to the nonsymmetric case. In general, when two countries form a monetary union, there will be an effect on third countries. Unfortunately without symmetry we do not find tractable analytical solutions for the matrices $A$ and $B$, so we illustrate the results below with numerical simulations.

In summary, forming a monetary union has a cost, relative to floating, in terms of reducing the smoothing effect of the exchange rate in the context of real shocks but also a benefit in that monetary shocks may be diversified across the members of the union. However, there are also more subtle effects in that within the union the real and monetary shocks of other monetary union members will have an effect on the common exchange rate.

\section{A Set of Simulations : the model in action}

So far our model provides a simple reduced form to understand many issues discussed in the literature regarding monetary unions. To further illustrate the workings of the model, in this section we report the results of a set of simulations. Our aim is to understand the implications for GDP volatility under different exchange rate regimes given different constellations of parameter values. Here, we consider the symmetric case where each country has the same weight, $w_{i j}$. In the empirical section below, we enhance the realism of the simulations by using weights calculated from the direction of trade statistics.

\subsection{Small versus large monetary shocks}

In the first simulation, the size of the monetary shocks (individual and systemic) are set to be $10 \%$ of the size of the real shocks. In this simulation all the $\beta$ 's for all the countries are set equal to one and the $\alpha$ parameter is set equal to 0.1 suggesting that floating exchange rates may smooth real shocks with a half-life of 6 periods. Figure 1 graphs each country's GDP volatility with different assumptions regarding how many countries form a monetary union. If all countries float, and as the model is totally symmetric, all countries have the same GDP volatility ( the variance in this case is 1.83). This is the axis closest to the reader. If country 1 and 2 form a monetary union, then their GDP volatility rises as shown at the extreme left of the graph. The cost of having a 
joint exchange rate in terms of not smoothing the individual real shocks outweighs the benefits of reducing the (small) monetary shocks. However, in this symmetric case, other countries are unaffected by country 1 and 2 forming a monetary union. As more countries join the monetary union, this is bad for the monetary union as the common exchange rate is less effective in smoothing the real shocks of each country. The opposite extreme is with all countries in the monetary union (one world currency), in which case they all have the same GDP volatility in this symmetric case. This is clearly the worst result for all producing the highest GDP volatility. 
Graph1: A World of Small Monetary Shocks

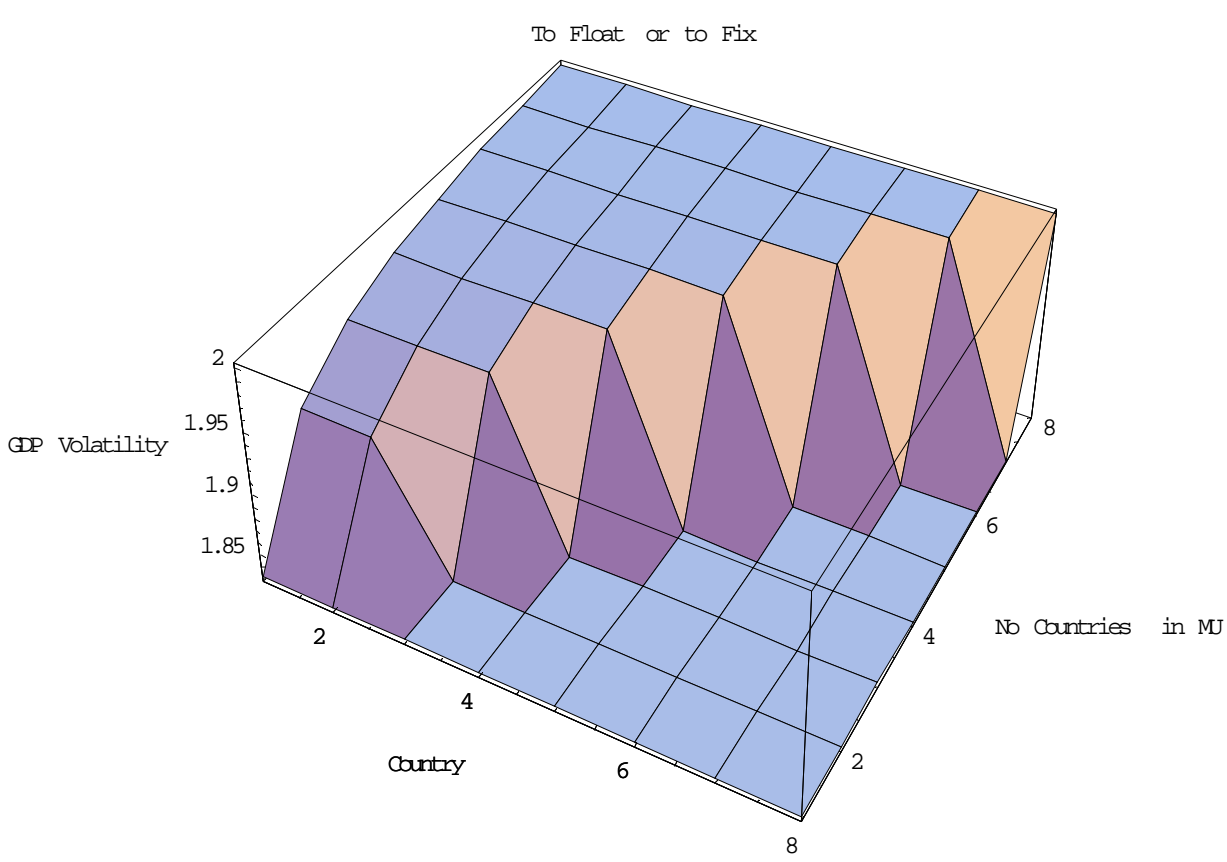

In a second simulation, we increase the size of the individual monetary shocks from $10 \%$ to double the size of the individual real shocks maintaining the other parameter values as before. The situation changes dramatically as illustrated in Graph 2. Now floating is the worst case with each country having the same and high GDP volatility as represented by the closest edge of the graph. If country 1 forms a monetary union with country 2 its GDP volatility falls as can be seen at the extreme left of the graph. The reason is that now these two countries diversify the high individual monetary shocks and this outweighs the cost of adopting a common exchange rate which smooths less effectively the (relatively small) real shocks. Again in this symmetric case, other countries are unaffected. As more and more countries join this union this is good for each country that joins and it is also good for the monetary union again due to the diversification effect. The best case is when all 
countries join the monetary union (one world currency) as represented by the far edge of Graph 2.

Graph 2: A World of Large Monetary Shocks

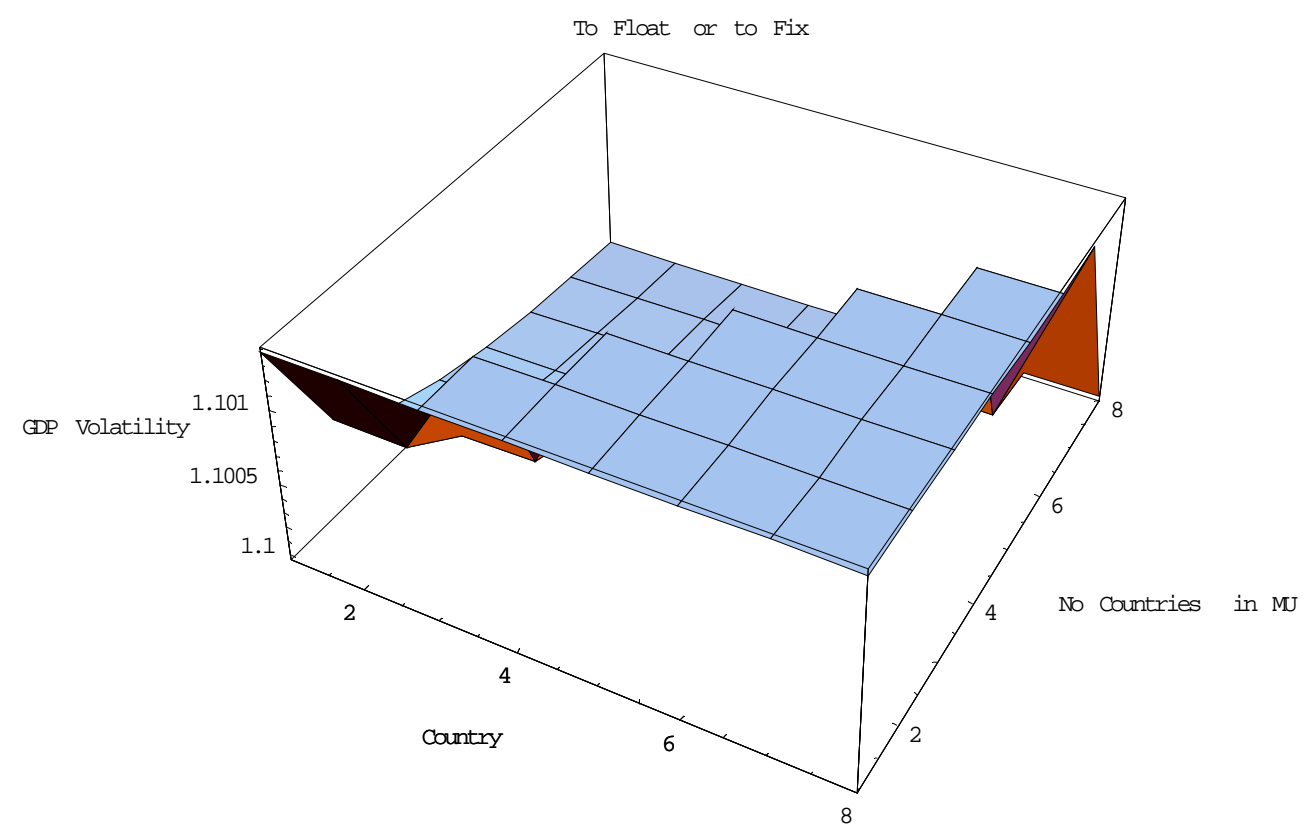

\subsection{An Anchor Country}

In this third simulation, we assume $n-1$ countries have the parameters of the previous simulation but we modify the parameters for the first country. In particular we consider this to be an anchor country with low individual monetary shocks equal to $50 \%$ of the individual monetary shocks of the other countries. Hence when all countries float, the anchor country has lower GDP volatility than the other countries. This is represented at the point closest to the reader in Graph 3 below. Along the right edge of the graph close to the reader, it can be seen that the GDP volatility of other countries is relatively high. However, if country 
2 now joins country 1 in a monetary union this is good for country 2 but bad for country 1 . As more countries enter the monetary union this is increasingly bad for the members of the union (the best result for country 2 is that only it forms a monetary union with the anchor) although the marginal increase in volatility falls as the size of the union increases.

\section{Graph 3: An Anchor Country}

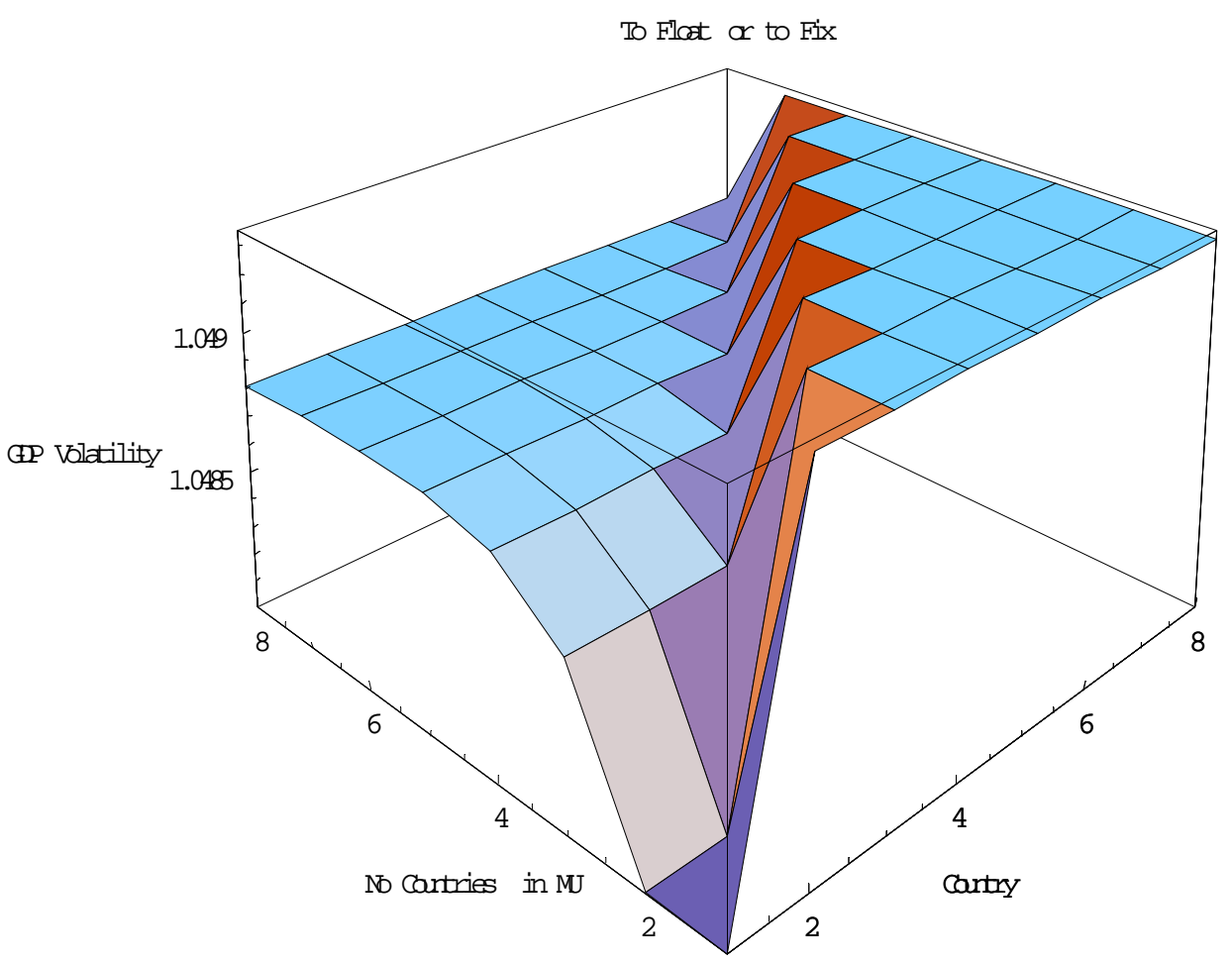

\subsection{A Natural Monetary Union}

In this simulation we postulate that there are two types of countries in the world. Countries 1 to 4 have large individual monetary and high and equal sensitivities to the real world shock $\left(\beta^{R}\right)$. These countries then form a natural monetary union as the cost of having a common 
exchange rate is reduced as they suffer similar real shocks and the benefit in terms of diversifying the large montary shocks is greater. Countries 5 to 8 have similar parameters to our first simulation such that they are natural floaters. To make the difference between the two groups more pronounced we reduce their sensitivities to the world systemic real shock to zero such that the cost of joining a monetary union is increased. The result of considering monetary unions between these eight countries is illustrated in Graph 4 below. If all countries float, the four first countries have considerably higher GDP volatility as they are subject to higher monetary shocks. It is beneficial for the first four countries to form a monetary union. In fact for each of these countries it is best to be in a monetary union with the other 3 . This is because it reduces the effect of the monetary shocks and as discussed there is little cost as the sensitivities to the world real systemic shock are all high and equal. On the other hand note that if country 5 joins the monetary union this is bad for country 5 and bad for the 4 existing members. As country 5 has low monetary shocks, and a different sensitivity (from that of the monetary union) to the world real shock, it pays a high price for the common currency. Also admitting country 5 to the monetary union is bad for the existing members as, in this case, the cost of having a country with very different real shocks outweighs the beneficial effect of admitting a country with low monetary shocks. 


\section{Graph 4: A Natural Monetary Union}

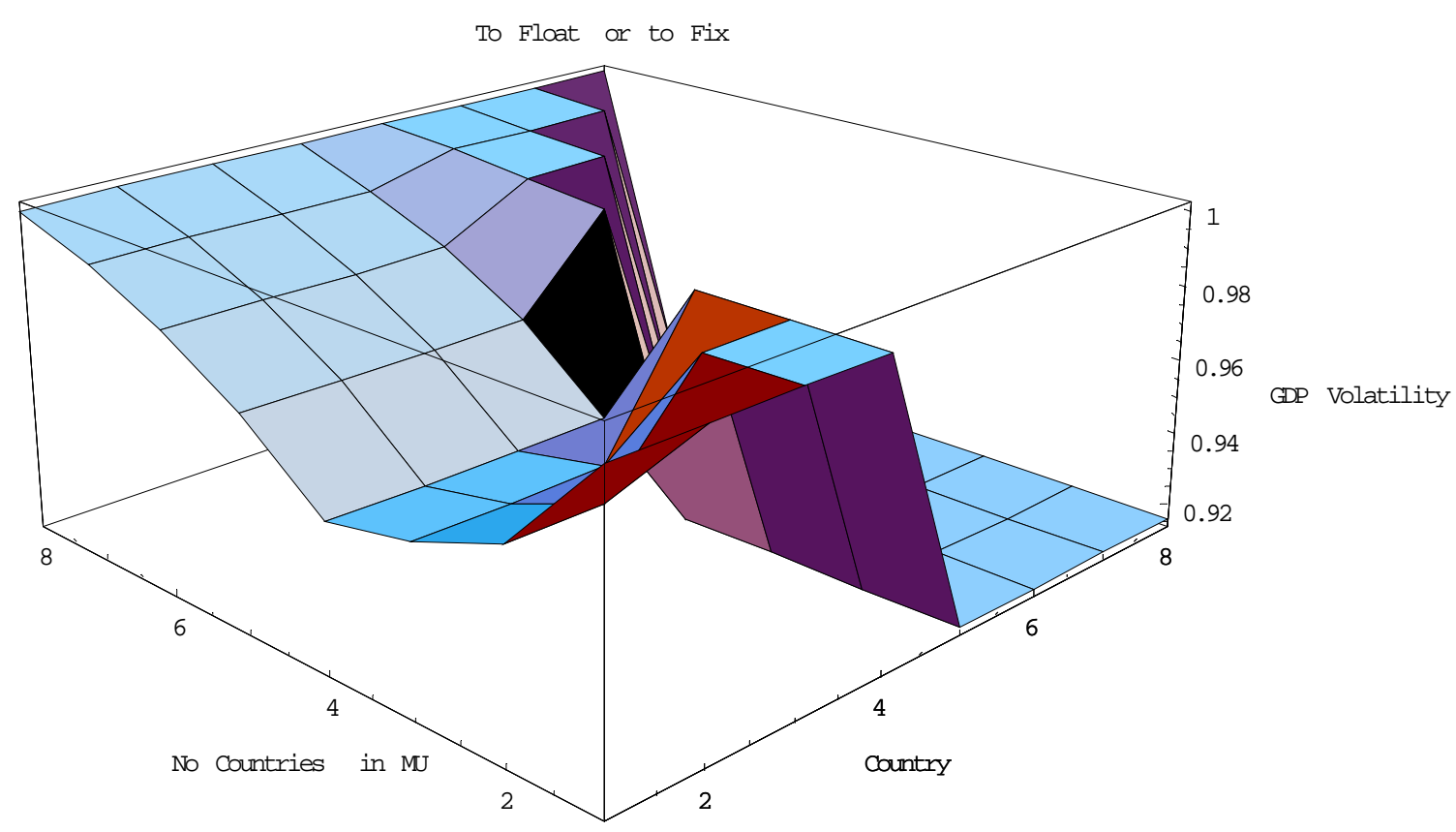

\section{EMU, Nafta and a One World Currency}

In this section we report the results of calibrating this reduced form to real data. In order to do this we must estimate 1) the systemic real and monetary factors, 2) the sensitivities of each country's real GDP and nominal exchange rate to those systemic factors, 3) the individual or non systemic real and monetary shocks, and finally, 4) the parameter $\alpha$ which governs how well a floating exchange rate that only responds to real shocks would smooth real GDP.

A natural way to extract the systemic factors is through a factor analysis. We work with the log changes in real GDP and of nominal exchange rates of the countries listed in Table 1. As we wish to analyze the effects of EMU, as well as other monetary arrangemets on individual EMU members, we need to consider data before the commencement of the Euro. Thus our quarterly data spans the period from 1Q 1980 to 4Q 1998. During this period, despite the several attempts to limit the volatility of nominal exchange rates, there was sufficient exchange rate 
fluctuation to allow us to estimate the required parameters ${ }^{10}$. The results of the factor analysis is included in Appendix 1. When we extract two factors using principal components, it turns out that one factor appears to explain more the real GDP movements while the second explains better the nominal exchange rate fluctuations. However, this allocation is not perfect and it is also well-known that the factors are not unique. Thus, we apply a quartimax rotation that attempts to explain each variable by the minimum number of factors. In our case, as we only admit two factors, it tends to increase the weight on the factor that explains most of a particular variable and reduces the weight on the other factor. This suits our purpose perfectly as the rotated factors then correspond more closely to a "real" factor that explains GDP movements and a "nominal" factor that explains nominal exchange rate movements. The quartimax rotation also maintains the orthogonality between the two factors ${ }^{11}$.

Having obtained two orthogonal factors in this way, we then run a Vector Autoregression (VAR) for each country including four lags of real GDP and the nominal exchange rate as endogenous variables and the two factors as exogenous variables. We do this for various reasons. First, a useful check on the selection of the factors is to assure that the "real factor" is significant in the equation for real GDP and not significant for movements in exchange rates and that the nominal or monetary factor is significiant in the equation for movements in the nominal exchange rate and not in the equation in real GDP. We find that this the case for all countries except in the equation for the French Franc where the systemic real factor appears to be very marginally significant - these results are detailed in Appendix 1. The fact that in general, the real factor drives real GDP's but not nominal exchange rates, and vice versa for the monetary or nominal factor (and that the two factors are orthogonal by construction), gives us some comfort that these systemic factors correspond fairly closely to the real and to the nominal shocks respectively.

The coefficients on the systemic factors in the VAR's are exactly the beta coefficients that we need to calibrate the model. The "real beta" is the coefficient on the real systemic factor entered as an exogenous variable in the VAR and the "nominal beta" is the coefficient on the nominal systemic factor in the VAR. In all cases, these coefficients are statistically significant. In Table 1, we give the estimated parameters for the countries that we incorporate in the simulations below.

\footnotetext{
${ }^{10}$ We measure all nominal exchange rates against the SDR basket.

${ }^{11}$ The version of the quartimax rotation we employ normalizes the variance of the factors to unity. This restriction implies that the factors are unique.
} 
Table 1: Parameter Estimates from Country Vector AutoRegressions

\begin{tabular}{|c|c|c|c|c|}
\hline & \multirow[b]{2}{*}{$\begin{array}{l}\text { Real } \\
\text { Beta }\end{array}$} & \multirow[b]{2}{*}{$\begin{array}{l}\text { Nominal } \\
\text { Beta }\end{array}$} & \multicolumn{2}{|c|}{ Standard Deviations } \\
\hline & & & $\begin{array}{l}\text { Individual } \\
\text { Real Shock }\end{array}$ & $\begin{array}{c}\text { Individual } \\
\text { Nominal Shock }\end{array}$ \\
\hline Germany & $0.26 \%$ & $-2.57 \%$ & $1.24 \%$ & $1.10 \%$ \\
\hline France & $0.28 \%$ & $-2.18 \%$ & $0.43 \%$ & $1.56 \%$ \\
\hline Italy & $0.41 \%$ & $-1.98 \%$ & $0.44 \%$ & $2.36 \%$ \\
\hline UK & $0.25 \%$ & $-1.23 \%$ & $0.48 \%$ & $3.27 \%$ \\
\hline Canada & $0.45 \%$ & $2.20 \%$ & $0.66 \%$ & $1.54 \%$ \\
\hline USA & $0.62 \%$ & $2.33 \%$ & $0.52 \%$ & $1.14 \%$ \\
\hline Japan & $0.01 \%$ & $-0.83 \%$ & $0.76 \%$ & $3.44 \%$ \\
\hline Australia & $0.54 \%$ & $2.54 \%$ & $0.61 \%$ & $3.44 \%$ \\
\hline Chile & $1.18 \%$ & $2.35 \%$ & $2.65 \%$ & $4.38 \%$ \\
\hline Mexico & $0.53 \%$ & $5.65 \%$ & $1.82 \%$ & $8.59 \%$ \\
\hline
\end{tabular}

Moreover, we take the standard deviation of the error of the real GDP equation and of the equation for the exchange rate as the standard deviation of the individual real and monetary shock respectively. This leaves us only with the parameter $\alpha$ to estimate. We calibrate this parameter such that the actual volatility of real GDP is close to the volatility suggested by the simulations of the theoretical model if all countries float. We find that with an $\alpha$ parameter close to 0.1 yields GDP volatilities in our simulations of a similar magnitude to actual GDP volatilities.

In each of the following simulations, we consider a single monetary union that incorporates the first 1 to $k$ countries inclusive. We present 2 different exercises a) EMU and expansions to EMU and b) A common currency for Nafta and extensions. For these simulations we employ the non symmetric version of the model and bilateral exchange rates now differ in importance with regards to smoothing GDP. We employ the OECD Direction of Trade Statistics to calculate the importance of each bilateral exchange rate, $s_{i j}$. We assume that the importance of the bilateral exchange rate between country $i$ and $j$ in smoothing the GDP of $i$ is related to the total exports and imports of $i$ to $j$ divided by the total amount of exports and imports of country $i$. In other words we assume that $w_{i j}=\frac{X_{i j}+M_{i j}}{\sum_{j} X_{i j}+M_{i j}}$ where $X_{i j}$ refers to the exports of country $i$ to country $j$ and $M_{i j}$ refers to the imports of country $i$ from country $j$. When the model is non-symmetric in this way, there is an effect on a non-member country if two or more countries form a monetary union. 


\subsection{Expanding EMU}

In this first simulation we consider G7 countries in the following order, 1) Germany, 2) France, 3) Italy 4) the UK, 5) Canada, 6) the US, 7) Japan with these followed by the rest of the world. The rest of the world is modelled as one large country. We introduce the beta coefficients and individual and systemic shock variances as estimated using the factor analysis and VAR modelling as described above ${ }^{12}$.

For the purposes of illustration, we normalize GDP volatility if all countries float to 100 (otherwise the differences in individual country GDP volatility swamp the changes in GDP volatility due to the effect of joining the monetary union). Graph 5 shows the results ${ }^{13}$. The leading left edge of the Graph has all countries floating. If Germany and France (countries 1 and 2), join a monetary union this corresponds to the number of countries in a monetary union being 2. If Germany, France and Italy join a monetary union then this variable is 3 etc. The Graph shows that the Euro is a clear cost for Germany (country 1) as its GDP volatility rises substantially as France and Italy join and in fact continues to rise (although to a lesser degree) as the UK, Canada and the US join as well. All in all, GDP volatility for Germany rises by about $4 \%$ if it forms a monetary union with France and $5.1 \%$ if the world adopts a single currency. Interestingly, a worst case for Germany is if the UK enters. In that case, GDP volatility is some $6 \%$ higher for Germany than if all floated. For France (country 2) there is a cost in joining a monetary union with Germany and while this cost falls if Italy joins, French GDP volatility remains higher than if France floated. However, if the UK also enters then the monetary union delivers roughly the same GDP volatility for France as floating. In the case of Italy (country 3), there is a cost if Germany and France form a monetary union and Italy stays out, but Italy benefits, even relative to floating, on entering. Italy benefits further if the UK enters. In the case of the UK (country 4), there is virtually no cost relative to all floating if the other European countries form a monetary union and a benefit to join the Euro of roughly $3.9 \%$ of GDP volatility. This result derives from the UK's high nominal shocks estimated in the pre Euro period.

What happens if the Euro zone is extended to be a world and not just a European monetary union? First, there is very little cost for Canada if Germany, France, Italy and the UK form a monetary union. However, if

\footnotetext{
${ }^{12}$ For the rest of the world we employ the average values of the parameters across the coutnries included in Table 1.

${ }^{13}$ Table A2.1 in Appendix 2 details the actual results.
} 
Canada (country 5) joins, this is very costly for Canada (GDP volatility rises by $10 \%$ relative to all floating). Interestingly if Canada joins this is good for all the members of the Euro zone and especially good for the UK, assuming the UK is a member. As expected, the cost for Canada of joining a monetary union with Europe diminshes substantially if the US also joins. In the case of the US (country 6), again there is very little cost due to the formation of the Euro even if this includes the UK. If Canada and the US enter this results in GDP volatility $3 \%$ higher for both the US and Canada, relative to all floating or relative to the current currency configeration with the Euro. Finally, we note that for Japan (country 7) and the rest of the world (country 8), there is little effect due to the formation of the Euro, but if the dollar-euro zone is created with the first 6 countries as members then this benefits Japan to the tune of about $2 \%$ GDP volatility but again with little effect on the rest of the world.

Finally, we can note that a one world currency has mixed effects for G7 relative to all floating or in comparison to the current configuration of the Euro. Relative to all floating, a one world currency would be worst for Germany and best for the UK. However, relative to the current configuration of the Euro, Germany has already paid substantial costs and a one world currency would only imply $1 \%$ higher GDP volatility. A one world currency would benefit France, Italy, the UK and Japan but represents a cost to the other $3 \mathrm{G} 7$ countries. 
Graph 5: EMU, the UK and a One World Currency

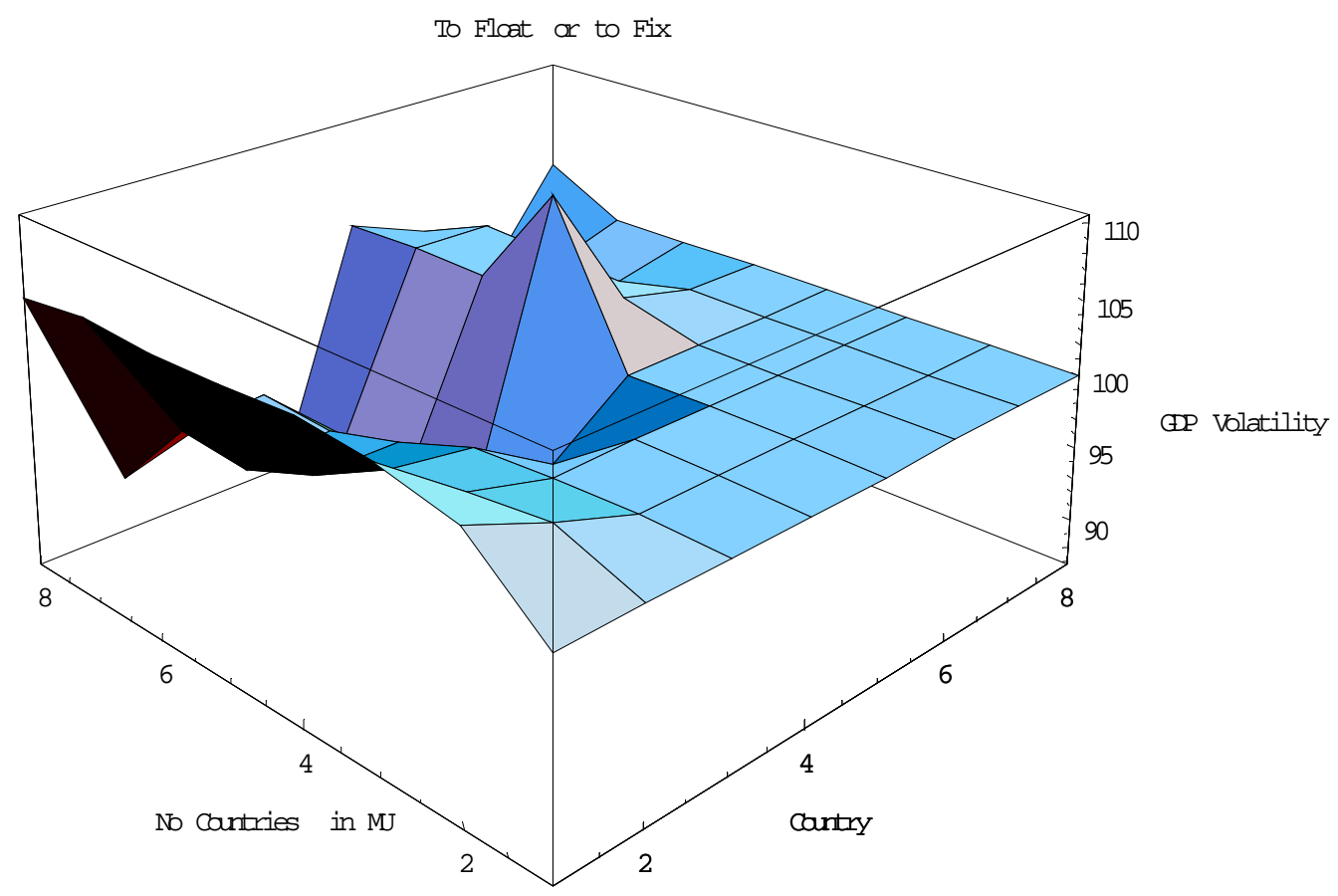

\subsection{A Common Currency for Nafta and Beyond}

In this simulation we consider a common currency for Nafta and therefore we need to change the order, adding further countries and centering the exercise on the US as the anchor country. The new ordering is then as follows, 1) USA, 2) Canada 3) Mexico 4) Chile 5) Australia 6) Japan 7) Germany 8) France 9) Italy and 10) the UK, and we include the rest of the world as country 11. Given this ordering, if only two countries form a monetary union, these will be US and Canada. If a third country enters, it would be Mexico, followed by Chile etc. In this case we introduce an additional weight. As discussed above, when countries of very different size form a monetary union then we believe it is more correct to define the change in GDP and the monetary shock of the monetary union as $\sum_{i=1, k} \pi_{i} \Delta G D P_{i}$ and $\sum_{i=1, k} \pi_{i} M_{i}$ respectively where $\sum_{i=1, k} \pi_{i}=1$ and

where $\pi_{i}$ is the relative size of country $i$ measured by GDP. This 
means that when the US forms a monetary union with Canada, the "monetary policy" of the monetary union is not a simple average of the two countries' policies, but rather reflects $95 \%$ the monetary policy of the US and $5 \%$ that of Canada.

The results of this simulation are illustrated in Graph 6 below and in Table A2.2 in Appendix 2. The first result is that a Nafta monetary union would be bad for the US and even worse for Canada, but would be to Mexico's advantage. Mexico's GDP volatility would decrease by $3 \%$ - a result of its relatively high monetary shocks. If Chile entered, this would be very bad for Chile (GDP volatility would rise by 7\%) and given Chile's small size, this hardly affects the other members of the union. Australia would not wish to enter this common currency but Japan would like to enter to make this a pacific currency area. Not surprisingly, given the results above, Germany would not wish to join and even if the whole current Euro area joined to make effectively a world common currency, this would be bad for Germany. However, France and Italy would gain if the Euro area joined to make a world currency. Moreover, consistent with our results above, the UK would suffer if it stayed out and would gain considerably from a world currency area. 
Graph 6: A Common Currency for Nafta and Beyond

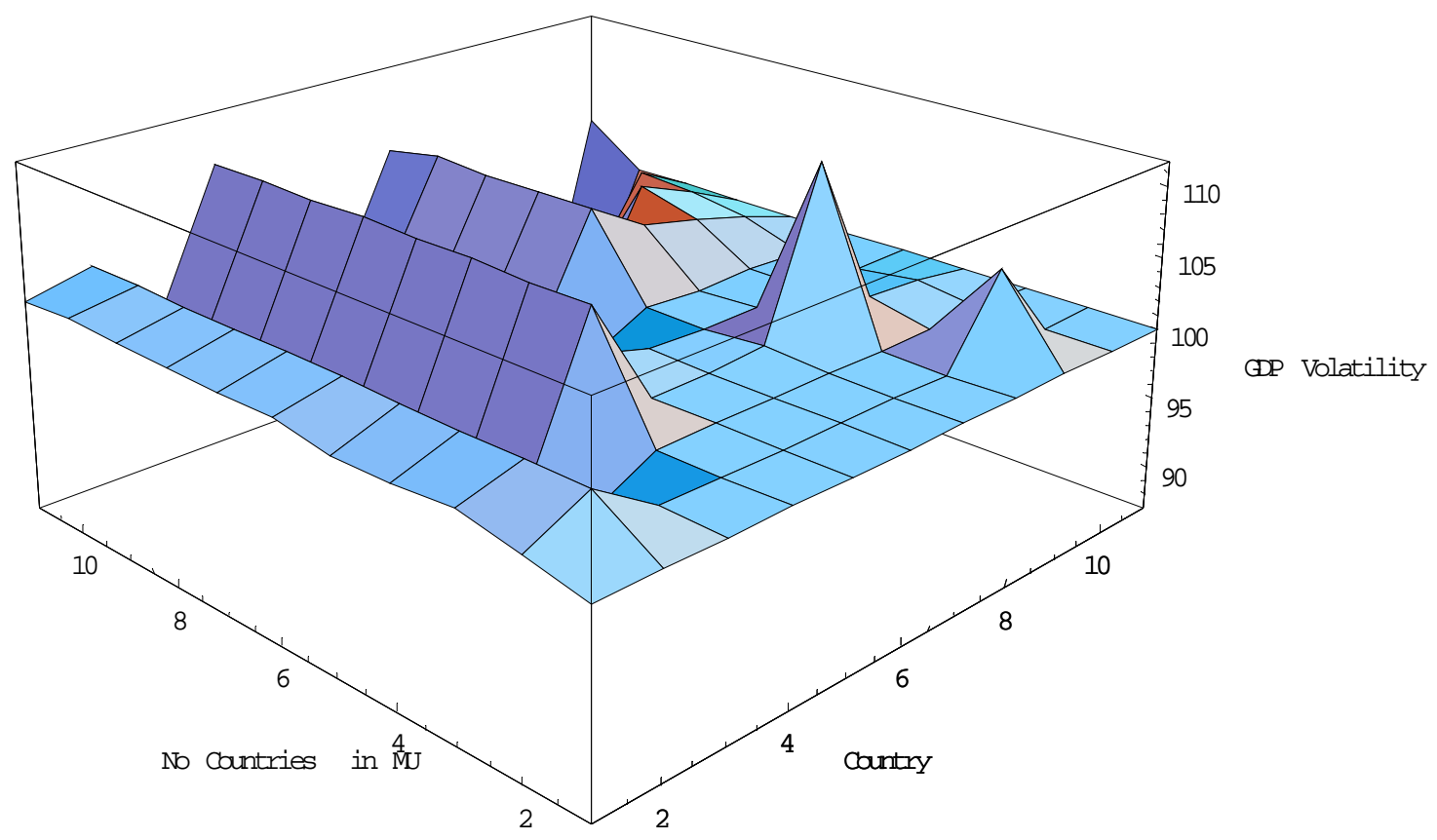

\subsection{Parameter Endogeneity}

As discussed above, these results assume that the beta coefficients and the individual monetary shocks remain constant despite the changes in monetary regimes discussed. However, we might expect the monetary and real "betas" to converge over time for the countries forming a monetary union. Moreover, it might be argued that with a multi-national central bank in charge of the monetary policy of a CU, this would boost central bank independence and credibility and hence the size of the monetary shocks would be reduced. We can also use the model to attempt to gauge how important these effects are.

In Graph 7, we illustrate how the benefits of the Euro change for its members as the process of convergence proceeds ${ }^{14}$. In this graph the left edge closest to the reader (degree of convergence zero) is the GDP volatility of all countries (G7 and the rest of the world in the order of the EMU simulation above: Germany, France, Italy, UK, Canada, US, Japan, ROW) assuming that all countries float and have their original

\footnotetext{
${ }^{14}$ The actual numbers for Graph 7 are given in Table A2.3 in Appendix 2.
} 
paramter values as above. The line corresponding to a degree of convergence of one, simulates GDP volatility given the existence of the Euro with Germany, France and Italy as members again with the original parameter values. Hence this repeats the line in Graph 5 above corresponding to the number of countries in the monetary union being 3 . As the degree of convergence increases we then adjust a) the real betas, b) the monetary betas and c) the individual monetary shocks of the 3 Euro members such that when the degree of convergence is 10, these parameters are all equal for the three countries and converge to the minimum value across the 3 countries. Most importantly, this means that the individual monetary shocks converge to the value for Germany.

The Graph illustrates that the Euro, even with full convergence, still represents a cost for Germany, France benefits from the Euro if convergence is more than about $50 \%$ and Italy gains from the Euro and gains even more as convergence proceeds. Italy's GDP volatility is reduced by $0.1 \%$ given its original parameters given Euro membership but by $14 \%$ if there is full convergence. Interestingly, the cost of the UK staying out rises as the three Euro member countries converge, but the effect is very small ( $0.16 \%$ of GDP volatility). And the US benefits as the three members of the Euro converge. As about $5 \%$ of US trade is with France and Italy, and as the individual monetary shocks of these countries diminish as convergence proceeds, this is likely due to the lower impact of these shocks on the Euro-dollar bilateral exchange rate and hence allows this exchange rate to smooth US shocks more effectively. 


\section{Graph 6: EMU and Convergence}

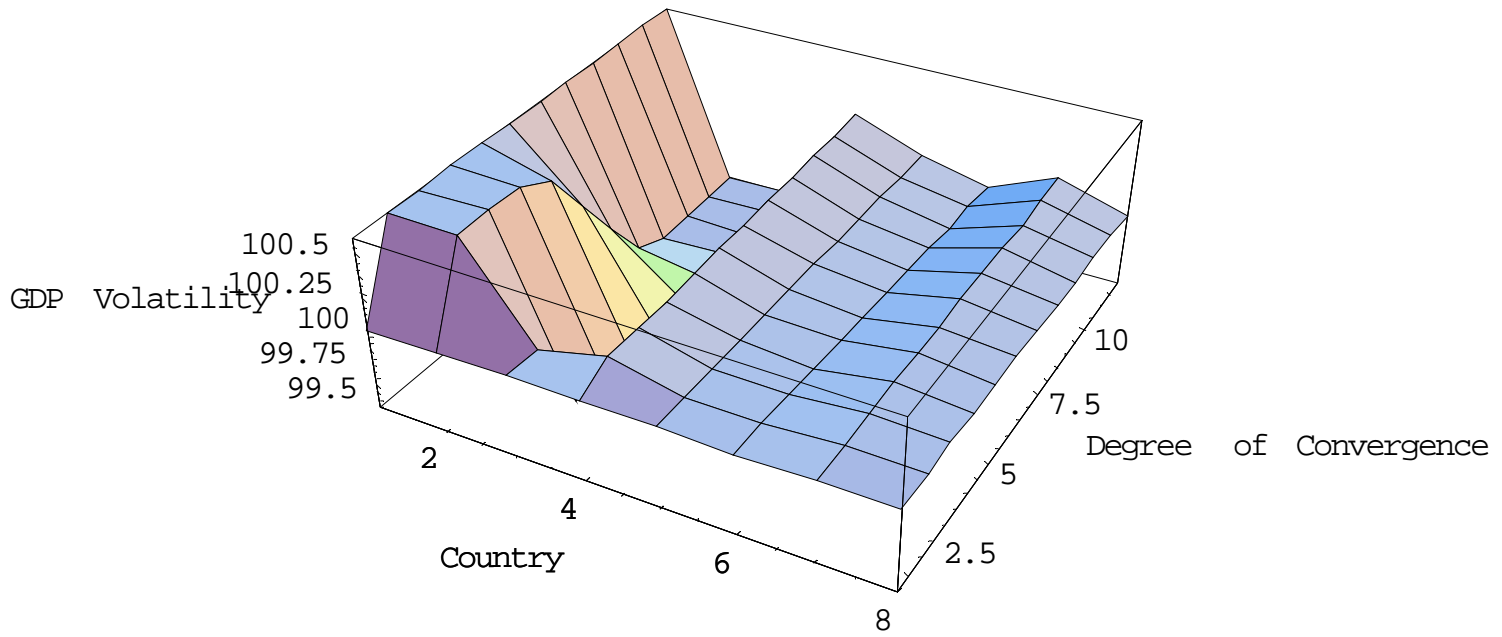

As detailed above, Euro membership for the UK represents a benefit for that country but a significant cost for Germany. We can also use the model to investigate if this conclusion changes significantly given convergence. The answer is no. While the UK benefits with a reduction in GDP volatility of about 3.9\% on Euro membership with the original parameters, this only increases to $4 \%$ with full convergence. While UK membership increases Germany's GDP volatility by $6.1 \%$ given the original parameters this is only reduced to $5.9 \%$ given full convergence.

Finally, suppose the UK, through greater central bank independence and the implementation of an inflation targetting regime, manages to reduce its individual monetary shocks from the value estimated in our period of floating exchange rates before the inception of the Euro, but continued to float. Would that give rise to a greater benefit as joining the Euro for the UK? We find that this is indeed the case. If the UK reduced its individual monetary shocks to $2.2 \%$, half the way from the 
estimated value of $3.3 \%$ towards Germany's estimated value (1.1\%), then this gives the UK the same benefit as joining the Euro (about 3.9\% of GDP volatility). And in that case, Euro membership would represent a cost to the UK of about $2 \%$ of GDP volatility - assuming no convergence in the other parameters. The UK would, however, still benefit from a one world currency. If the UK reduced its individual monetary shocks all the way to Germany's estimated $1.1 \%$, then this reduces UK GDP volatility by $9.5 \%$ if the UK continues to float and Euro membership becomes more costly - over 7\% of GDP volatility.

Turning to the case of Nafta, above we found that a Nafta monetary union was a cost for the US, a greater cost for Canada but a benefit for Mexico. If we allow the parameters of the countries concerned to converge to US values, do these results change? In fact, the broad conclusions remain the same. However, we find that convergence to US parameter values actually implies a cost for Canada and Mexico. While convergence implies Mexico's individual monetary shocks are reduced from $8.6 \%$ to about $1.1 \%$, the common currency monetary policy is dictacted essentially by the US anyway, so that once Mexico has joined, its monetary shock parameters are essentially irrelevant. On the other hand the US's real beta is higher than both Canada's and Mexico's so if the latter countries' real betas converge to that of the US then this actually represents a cost for them. As the US economy dwarf's that of its neighbours, Canada's and Mexico's convergence produces only a very slight reduction in the small costs of a Nafta monetary union for the US.

\section{Conclusions}

In this paper, we have developed a simple theoretical framework that might be thought of as a reduced form of the OCA conditions capable of being extended to an $n$-country world. This allows us to consider the costs and benefits, in tems of GDP volatility, of joining a monetary union but also a set of third party impacts including the effect on other members of the union and non members. The model combines a factor approach with systemic and individual shocks, with the idea that for some sorts of shocks it is valuable to have exchange rate flexibility (the real shocks) whereas for other (monetary) shocks, flexibility may represent a cost.

A set of simulations shows the model in action. Depending on parameter values, floating or a monetary union might be the best option for 
a particular country and the optimal composition of a monetary union may change. In general, as more countries join a monetary union, there is a tradeoff between the diversification effect (diversifying individual monetary shocks) against a cost of including more countries with different sensitivities to the systemic real shock - the "real betas". The exchange rate of the monetary union will then tend to reflect less the monetary shocks but also will reflect less the real shocks of a particular country member. The smoothing role of a floating exchange rate is then diminished but the cost of a floating exchange rate more vulnerable to nominal shocks is also diminished.

We then present two empirical applications of the model. We employ a principal component technique combined with a quartimax rotation in order to define a systemic real and a systemic nominal factor. We then estimate VAR's country by country introducing the systemic factors as exogenous variables and obtain the necessary parameter estimates for the model. The first application considers the introduction of the Euro, UK membership and the possible extension of the Euro to a one world currency. We find that the Euro is a cost for Germany and France but a benefit to Italy and the UK. However, UK membership increases the cost to Germany. Extending the Euro to a truly world currency would benefit France, Italy, the UK and Japan but represents a cost to the other $3 \mathrm{G} 7$ countries. In our second empirical estimation, we focus on the debate regarding a common currency for Nafta and beyond. We find that a common currency would be a cost for the US and especially Canada but would benefit Mexico. Chile would certainly not wish to enter this common currency area nor would Australia but Japan would benefit from a pan-pacific currency including Nafta and the other countries mentioned. As the currency is extended to a world currency we obtain the same results as above. Germany and the US and Canada suffer, but only a little more than the current configeration of the Euro and the world currency is good for France, Italy and the UK relative to floating. Perhaps of interest to the countries concerned, Mexico would prefer only a common currency for Nafta than a world currency but Chile, that prefers a float, is indifferent between these two alternatives.

We consider this as very much a first attempt at applying a simple but general and flexible theoretical framework to the problem of optimal currency areas. We offer the results as suggestive rather than definitive. We hope that the theoretical ideas of how to model OCA conditions in a truly $n$-country case may provoke further interest in both the theoretical and empirical aspects. In particular trying to pin down what the real and the monetary individual and systemic shocks are, how monetary 
policy might be introduced and how the shocks and policy rules might be best estimated in the context of such an analysis are all potential areas where further progress might be made. We believe the overall theoretical framework could be further developed and used to analyze a set of interesting questions in multi-country versions of optimal currency area theory and in many practical applications.

\section{References}

Bayoumi, T. (1994) "A formal theory of Optimum Currency Areas" IMF Staff Papers, 42(4): 537-54.

Bayoumi, and Eichengreen, B. (1994) "Monetary and exchange rate arrangements for NAFTA" Journal of Development Economics, 43: 125165.

Bean, C. R. (1992) "Economic and monetary union in Europe" Journal of Economic Perspectives, Fall: 31-52.

Buiter, W (1999) "Optimal currency areas: why does the exchange rate matter?" Sixth Royal Bank of Scotland/Scottish Economic Society Annual Lecture, mimeo University of Cambridge.

Carrera, J. y F. Sturzenegger (2000) "Coordinación de políticas macroeconómicos en el mercosur" Fundación Gobierno y Sociedad, Buenos Aires.

Calvo, G. (2002) "Explaining sudden stop, growth collapse and BOP crisis: the case of distortionary output taxes" Paper prepared for Anual IMF Research Conference, Mundell Fleming Lecture, Nov 72002 and mimeo Inter American Development Bank, Washington DC.

Mckinnon, R.I. (1963) "Optimum currency areas" American Economic Review, 53, pp 717-25.

Masson, P and M Taylor (1994) "Optimal currency areas: a fresh look at the traditional criteria" in Pierre Siklos ed. Varieties of Monetary Reform, pp 23-44, Kluwer, Boston, Mass. USA.

Mundell, R. A. (1961) "A theory of optimum currency areas" American Economic Review, 51, pp 657-75.

Poole, W (1970) "Optimal choice of monetary policy instruments in a simple stochastic macromodel" Quarterly Journal of Economics, 84, pp. 197-216.

Willett, T. W. (1999) "The OCA approach to exchange rate regimes: a perspective on recent developments",

paper prepared for conference on "Should Canada and the US adopt a common currency" Western Washington University, April 30, 1999 and mimeo, Claremont Graduate School, CA. 


\section{Appendix 1}

Table A1.1: Factors Extracted from changes in real GDP and changes in nominal exchange rates:

Principal Components and subject to Quartimax rotation

Component Matrix ${ }^{a}$

\begin{tabular}{|l|r|r|}
\hline \multirow{2}{*}{} & \multicolumn{2}{|c|}{ Component } \\
\cline { 2 - 3 } d_gdp_usa & \multicolumn{1}{|c|}{1} & \multicolumn{1}{|c|}{2} \\
d_gdp_jap &,$- 1234 \mathrm{E}-03$ & $2,948 \mathrm{E}-02$ \\
d_gdp_ger & $3,572 \mathrm{E}-02$ &, 151 \\
D_GDP_UK &, 207 &, 561 \\
d_gdp_fra &, 293 &, 497 \\
d_gdp_can & $-3,82 \mathrm{E}-02$ &, 606 \\
d_gdp_aus & $4,424 \mathrm{E}-03$ &, 676 \\
d_gdp_ity &, 242 &, 618 \\
d_gdp_chi & $4,651 \mathrm{E}-02$ &, 398 \\
d_gdp_mex & $-1,39 \mathrm{E}-02$ &, 190 \\
D_FX_USA &, 883 & $-8,71 \mathrm{E}-02$ \\
D_FX_JAP &,- 141 &, 100 \\
D_FX_GER &,- 909 & $9,084 \mathrm{E}-02$ \\
D_FX_UK &,- 351 & $-3,16 \mathrm{E}-02$ \\
D_FX_FRA &,- 833 & $-3,42 \mathrm{E}-02$ \\
D_FX_CAN &, 812 & $-3,01 \mathrm{E}-02$ \\
D_FX_AUS &, 544 &,- 199 \\
D_FX_ITY &,- 686 & $-4,47 \mathrm{E}-02$ \\
D_FX_CHI &, 466 &,- 268 \\
D_FX_MEX &, 518 &,- 105 \\
\hline
\end{tabular}

Extraction Method: Principal Component Analysis a. 2 components extracted
Rotated Component Matrix ${ }^{\text {a }}$

\begin{tabular}{|l|r|r|}
\hline & \multicolumn{2}{|c|}{ Component } \\
\cline { 2 - 3 } & \multicolumn{1}{|c|}{1} & \multicolumn{1}{|c|}{2} \\
\hline d_gdp_usa &,- 106 &, 735 \\
d_gdp_jap &,- 124 & $1,060 \mathrm{E}-02$ \\
d_gdp_ger & $1,213 \mathrm{E}-02$ &, 155 \\
D_GDP_UK &, 119 &, 586 \\
d_gdp_fra &, 214 &, 536 \\
d_gdp_can &,- 131 &, 593 \\
d_gdp_aus & $-9,92 \mathrm{E}-02$ &, 669 \\
d_gdp_ity &, 145 &, 647 \\
d_gdp_chi & $-1,49 \mathrm{E}-02$ &, 400 \\
d_gdp_mex & $-4,28 \mathrm{E}-02$ &, 186 \\
D_FX_USA &, 886 & $4,919 \mathrm{E}-02$ \\
D_FX_JAP &,- 155 & $7,742 \mathrm{E}-02$ \\
D_FX_GER &,- 912 & $-4,95 \mathrm{E}-02$ \\
D_FX_UK &,- 342 & $-8,49 \mathrm{E}-02$ \\
D_FX_FRA &,- 818 &,- 161 \\
D_FX_CAN &, 807 & $9,467 \mathrm{E}-02$ \\
D_FX_AUS &, 568 &,- 114 \\
D_FX_ITY &,- 671 &,- 149 \\
D_FX_CHI &, 502 &,- 193 \\
D_FX_MEX &, 528 & $-2,43 \mathrm{E}-02$ \\
\hline
\end{tabular}

Extraction Method: Principal Component Analysis. Rotation Method: Quartimax with Kaiser Normalization. a. Rotation converged in 3 iterations. 


\section{Appendix 2}

Table A2.1: EMU, the UK and Beyond

\begin{tabular}{|c|r|rrr|r|r|r|r|r|r|}
\hline \multicolumn{2}{|c}{} & \multicolumn{8}{c|}{ GDP Volatility (Normalized) } \\
\cline { 3 - 10 } \multicolumn{1}{|c}{} & & Germany & France & \multicolumn{1}{c|}{ Italy } & UK & Canada & \multicolumn{1}{c|}{ US } & Japan & ROW \\
\hline & $\mathbf{1}$ & 100.00 & 100.00 & 100.00 & 100.00 & 100.00 & 100.00 & 100.00 & 100.00 \\
Numbers of & $\mathbf{2}$ & 104.34 & 102.02 & 100.03 & 100.02 & 100.00 & 99.99 & 100.01 & 99.99 \\
Countries in & $\mathbf{3}$ & 105.61 & 101.45 & 99.99 & 100.11 & 100.00 & 100.00 & 100.02 & 100.01 \\
Monetary & $\mathbf{4}$ & 106.07 & 100.49 & 99.49 & 96.12 & 100.01 & 100.02 & 100.02 & 100.01 \\
Union & $\mathbf{5}$ & 105.71 & 97.81 & 97.59 & 93.33 & 110.11 & 101.26 & 100.05 & 99.97 \\
& $\mathbf{6}$ & 105.53 & 95.72 & 96.12 & 90.94 & 102.90 & 102.65 & 98.85 & 99.98 \\
& $\mathbf{7}$ & 105.79 & 96.15 & 96.55 & 91.32 & 103.08 & 103.01 & 98.22 & 99.98 \\
& $\mathbf{8}$ & 105.11 & 90.56 & 92.42 & 87.40 & 102.93 & 100.80 & 95.92 & 102.75 \\
\hline
\end{tabular}

Table A2.2: Nafta Monetary Union and Beyond

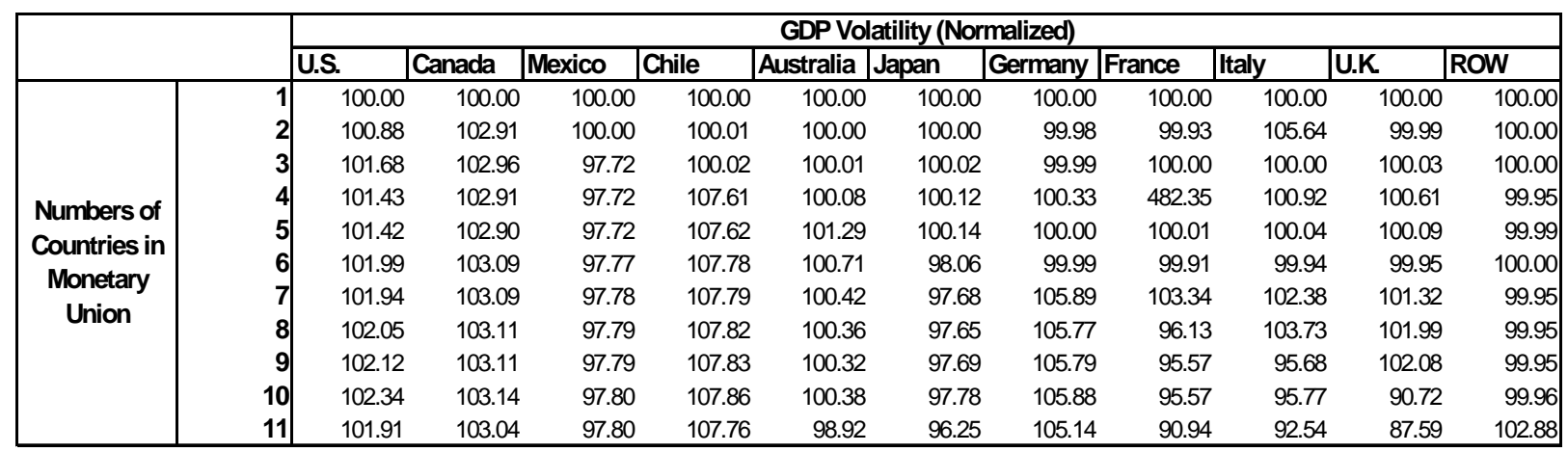


Table A2.2: EMU, the UK and Beyond with Convergence

\begin{tabular}{|c|c|c|c|c|c|c|c|c|c|}
\hline \multirow{4}{*}{$\begin{array}{l}\text { Original } \\
\text { Parameters }\end{array}$} & & \multicolumn{8}{|c|}{ GDPVolatility (Normalized) } \\
\hline & & Germany & France & Italy & UK & Canada & US & Japan & ROW \\
\hline & Hoat & 100.00 & 100.00 & 100.00 & 100.00 & 100.00 & 100.00 & 100.00 & 100.00 \\
\hline & $\mathrm{EMU}$ & 105.61 & 10145 & 99.99 & 100.11 & 100.00 & 100.00 & 100.02 & 100.01 \\
\hline \multirow{10}{*}{$\begin{array}{l}\text { Degree of } \\
\text { Convergence }\end{array}$} & $10 \%$ & 105.58 & 10112 & 98.44 & 100.11 & 100.00 & 99.99 & 100.03 & 100.01 \\
\hline & $20 \%$ & 105.55 & 100.80 & 96.92 & 100.12 & 100.00 & 99.97 & 100.03 & 100.00 \\
\hline & $30 \%$ & 105.52 & 100.47 & 95.44 & 100.12 & 99.99 & 99.96 & 100.04 & 99.99 \\
\hline & $40 \%$ & 105.49 & 100.15 & 93.98 & 100.13 & 99.99 & 99.95 & 100.04 & 99.99 \\
\hline & $50 \%$ & 105.46 & 99.83 & 92.56 & 100.13 & 99.99 & 99.94 & 100.05 & 99.98 \\
\hline & $60 \%$ & 105.43 & 99.51 & 91.17 & 100.14 & 99.99 & 99.92 & 100.05 & 99.97 \\
\hline & $70 \%$ & 105.40 & 99.19 & 89.83 & 100.14 & 99.98 & 99.91 & 100.06 & 99.96 \\
\hline & $80 \%$ & 105.37 & 98.87 & 88.52 & 100.15 & 99.98 & 99.90 & 100.06 & 99.96 \\
\hline & $90 \%$ & 105.35 & 98.55 & 87.25 & 100.15 & 99.98 & 99.89 & 100.06 & 99.95 \\
\hline & $100 \%$ & 105.32 & 98.24 & 86.02 & 100.16 & 99.98 & 99.88 & 100.07 & 99.94 \\
\hline
\end{tabular}

